\title{
Information Modeling of Earthquake-damaged Reinforced Concrete Structures
}

\section{Ling Ma ${ }^{1}$, Rafael Sacks ${ }^{2}$ and Reem Zeibak-Shini ${ }^{3}$}

Abstract: Accurate and reliable information about buildings can greatly improve postearthquake responses, such as search and rescue, repair and recovery. Building Information Modeling (BIM), rapid scanning and other assessment technologies offer the opportunity not only to retrieve as-built information but also to compile as-damaged models. This research proposes an information model to facilitate the data flow for post-earthquake assessment of reinforced concrete structures. The schema development was based on typical damage modes and the existing Industry Foundation Class (IFC) schema. Two examples of damaged structures from recent earthquake events, compiled using an experimental damage modeling software, illustrate the use of the data model. The model introduces two new classes, one to represent segments of building elements and the other to model the relationships between segments and cracks. A unique feature is the ability to model the process of damage with a binary tree structure. Methods for exporting asdamaged instance models using IFC are also discussed.

Keyword: IFC, building information modeling, damage assessment, post-earthquake responses

\footnotetext{
${ }^{1}$ Postdoctoral Researcher, Virtual Construction Laboratory, National Building Research Institute, Technion - Israel Institute of Technology, Haifa 32000, Israel +972-4-8292245, lingma@technion.ac.il

${ }^{2}$ Assoc. Prof., Head Dept. of Structural Engineering and Construction Management, Technion - Israel Institute of Technology, Haifa 32000, Israel +972-4-8293190, cvsacks@ technion.ac.il

${ }^{3}$ PhD Candidate, Virtual Construction Laboratory, National Building Research Institute, Technion - Israel Institute of Technology, Haifa 32000, Israel +972-4-8293120, reemz@technion.ac.il
} 


\section{Introduction}

Earthquakes affect millions of people and cause extensive damage to buildings and other structures. In the United States alone, the average economic loss from earthquakes is approximately $\$ 4.4$ billion a year [1] . Search and Rescue (S\&R) operations begin immediately once an earthquake has occurred, and recovery, including repair and renovation or demolition of damaged buildings follows. Both require rapid assessment of the damage to great numbers of buildings [2], because clear and accurate information is needed to support decisions about search and rescue safety, habitability and repair of the buildings.

In planning S\&R operations, the primary information needed is the location of 'airpockets' in the building in which survivors may be trapped and any possible pathways to reach them [3]. The voids and pathways are defined by the geometry and the new placement of the building's components, including structural elements and nonstructural elements that might be relevant for $S \& R$ teams, such as major ducts and pipes, partitions and fixed furniture. Structural element information should include the configuration of the structural system and the type, detailing, connectivity, material strength and condition of its structural elements. Lack of information seriously hampers rescuers' ability to locate and reach survivors while time is of the essence. In current practice, as-built information of the building is at best available in $2 \mathrm{D}$ drawing sets.

In the recovery phase, buildings may be approved for occupation, slated for repair or condemned for demolition. The assessment and any planning for renovation require detailed comparison of building elements' status before and after the earthquake. The Federal Emergency Management Agency (FEMA) guide to earthquake damage assessment 
(FEMA 306) [4] details what information should be collected and how it should be obtained. Section 3.8 of the guide prescribes how the information should be documented, however, it doesn't consider any digital documentation, and it also requires preparation of 2D plans, sections and elevations.

Given the development of Building Information Modeling (BIM), cloud storage and various rapid data acquisition technologies, much of the needed information can be derived automatically or semi-automatically, stored and delivered using BIM tools. As-built information can already be provided in BIM formats using existing applications. Recent research efforts have proposed pre-installed data-storage devices to store digital as-built information [5] and the use of mobile devices for smart retrieval of information has been implemented and tested [6]. Damaged buildings can be surveyed by engineers using traditional methods, such as those prescribed in FEMA 306 [4], but methods are also being developed for acquisition of the damaged states of building façades using laser scanning $[7,8]$ and photogrammetry $[9,10]$ and for derivation of the full damaged state of structures using structural collapse simulation models and the façade data [11]. In addition, a reliable connection between as-built information and damage inspection records for conducting joint pre- and post-earthquake assessment studies also attracts fairly scientific interests [12].

Application of BIM to S\&R and to recovery phase operations demands development of a data model to represent the necessary information. The schema of such a model must support parametric, semantic and interoperable representation of a building not only in an 'as-designed' or an 'as-built' state, but also in an 'as-damaged' state. This paper reports the development of the schema for the domain of reinforced concrete (RC) buildings. The data model is based on the existing IFC specification [13] due to its broad acceptance as an open 
international standard and its ability to fully represent the as-built state. The focus of the paper is therefore on the object classes, their properties, and their interrelationships that are all needed to represent the as-damaged state concepts such as segments of building elements, plastic hinges and cracks.

The next section reviews the possible modes of damage for $\mathrm{RC}$ structures, the ways in which they develop in structural components and the information required for postearthquake response. This review provided the basis for information analysis to derive the new information to be modeled. The following section describes the analysis and details the derived building model schema. Examples of instantiation of as-damaged models are illustrated. The section on IFC outlines what extensions would be necessary to support asdamaged modeling of buildings.

\section{Information requirements in post-earthquake responses}

\subsection{Damage modes of RC structures and their components}

Reinforced concrete frames are the predominant construction method for residential, commercial and public buildings taller than two stories worldwide, and are therefore of primary interest in the context of earthquake recovery. At the level of detail of structures as a whole, their damage and collapse modes have been classified in general terms that are commonly used for buildings with other construction methods types as well. At the component level, reinforced concrete structures have specific modes of behavior and sustain damage in ways that are determined by the interaction of concrete and reinforcing steel. 
At the least detailed level, damage classification is limited by the methods of data collection (satellite imagery, aerial photogrammetry or LiDAR scanning) [14]. At a resolution of meters or coarser, the seismic damage can only be detected and classified at the building level [14]. Table 1 outlines whole structure damage modes based on the 15 categories defined by Schweier and Markus [15]. The geometric measures needed to determine the damage mode of the whole building, and to evaluate the severity of a particular damage mode, include the orientation of the structure, the total height reduction at various points, the overall volume reduction, and the integrity of the external facades.

Table 1. Modes of damage of RC buildings (based on Schweier and Markus [15]).

\begin{tabular}{|c|c|c|}
\hline $\begin{array}{l}\text { Damage } \\
\text { Mode }\end{array}$ & $\begin{array}{l}\text { Sub- } \\
\text { category }\end{array}$ & Mechanism \\
\hline \multirow[t]{2}{*}{$\begin{array}{l}\text { Inclining or } \\
\text { overturning }\end{array}$} & $\begin{array}{l}\text { Whole } \\
\text { building }\end{array}$ & $\begin{array}{l}\text { The building overturns, or it inclines due to first floor } \\
\text { supports failing on one side }\end{array}$ \\
\hline & $\begin{array}{l}\text { Partial } \\
\text { inclined } \\
\text { plane or } \\
\text { overturn }\end{array}$ & $\begin{array}{l}\text { The supports of floor slabs or roof collapse on one side } \\
\text { but withstand on the opposite side, resulting in partial } \\
\text { inclined planes or overturning of parts of some floors or } \\
\text { layers. }\end{array}$ \\
\hline \multirow[t]{2}{*}{$\begin{array}{l}\text { Multi-layer } \\
\text { collapse }\end{array}$} & Partial & $\begin{array}{l}\text { Some floors or parts of floors collapse within the } \\
\text { building }\end{array}$ \\
\hline & Outspread & $\begin{array}{l}\text { Floors detach from one another and spread apart on } \\
\text { collapsing }\end{array}$ \\
\hline
\end{tabular}




\begin{tabular}{|c|c|c|}
\hline \multirow[t]{2}{*}{$\begin{array}{l}\text { Pancake } \\
\text { collapses }\end{array}$} & Single floor & $\begin{array}{l}\text { A particular floor, usually where the shear resistance is } \\
\text { lower than that of the rest of the floors, fail and collapse } \\
\text { almost uniformly. The weaker, pancaked floor may be at } \\
\text { the bottom of the building, at its top, or at some } \\
\text { intermediate level. }\end{array}$ \\
\hline & $\begin{array}{l}\text { Multiple } \\
\text { floors }\end{array}$ & $\begin{array}{l}\text { As above, but with multiple weaker floors pancaking } \\
\text { together. In some cases, all the floors pancake on one } \\
\text { another. }\end{array}$ \\
\hline \multirow[t]{2}{*}{ Heap of debris } & Complete & $\begin{array}{l}\text { All structural elements fail, no parts of the original } \\
\text { structure (frames, cores, etc.) are discernible. }\end{array}$ \\
\hline & Partial & $\begin{array}{l}\text { Some structural components and systems survive within } \\
\text { the heap of debris, such as vertical components, building } \\
\text { cores, horizontal planar systems, or entire lower floors. }\end{array}$ \\
\hline \multicolumn{2}{|c|}{ Overhanging elements } & $\begin{array}{l}\text { Parts of the external façades are destroyed, but the slab, } \\
\text { beams or roof above remain in their original position. }\end{array}$ \\
\hline
\end{tabular}

At $1 \mathrm{~m}$ resolution or less, which can be measured using terrestrial laser scanning or photogrammetry, detection and identification of damage to building components becomes possible. The as-damaged shape and condition of a damaged component depends on the sequence in which local sections of the structural member sustain displacement, cracking and eventually failure. The development of damage at any given section is dependent on the development of damage at other sections, because the reinforcement yields, the concrete 
is cracked or crushed at those locations where the stresses applied exceed capacity, and the component behavior changes from the original structural design intent.

\section{1) Surface cracking}

In general, cracks are the precursor and sign of structural damage. Until cracks are sufficiently developed to split building components into pieces of concrete, they only appear as texture on the surfaces of building components.

2) Spalling and delamination

Spalling or delamination occur as a result of the development of cracks, which form parallel to the principal compression stresses [4]. Due to the concrete's characteristic of brittleness and the containment effect of reinforcement, spalling usually occurs up to the cover depth of the RC components. Pieces or regions of concrete consequently become separated from the surface of a building element and fallen away revealing the reinforcement. Delamination usually occurs if the components are plastered or have a stone/brick cladding, where the layers of the decorative materials separate and fall away.

\section{3) Bending and buckling}

Flexural cracks typically initiate at the extreme fiber of a section and propagate towards the section's neutral axis. Opposing flexural cracks in both directions often join with each other to form a relatively straight crack through the entire section [4]. Bending usually occurs in beams and slabs, while buckling usually occurs in columns. Both manifest as a curvature of the neutral axis of a longitudinal element or as a curvature along the surface of a plate element. 
4) Shearing and breaking

Associated with high bending moments, high shear demand produces cracks perpendicular to the neutral axis of the underlying components. The cracks further result in component shearing or breaking. Both of the two damage modes split the component into distinct segments. Rebar remains continuous, albeit ductile, across the two resulting segments in the case of shearing, while the segments are completely disconnected in the case of breaking. The separation of segments is highlighted in this damaged mode.

Modeling of the damage sustained by building components depends to a large extent on the identification of significant cracks on components and on the geometric features of the resulting segments, including the reduced volume shapes and their relative location and orientation. The damage modes of whole buildings can in turn be derived from the state of their components.

\subsection{Use cases for compilation of as-damaged building models}

How would a digital as-damaged building model be compiled and how would it be used? The possible information 'use-cases' have bearing on the level of detail required for geometry and properties. The following three modes may be used independently or in combination with one another.

The first mode of acquisition is large-scale damage assessment of the affected region. Emerging applications of aerial imaging techniques are making it possible to rapidly acquire point-cloud and image data describing damaged buildings [16,17]. As a macroscopic solution, these techniques can only provide general damage at building block level $[15,18]$. 
The second mode considered is on-site assessment using a portable tablet computer, in which an as-damaged model would be compiled directly by a surveyor, replacing traditional 'pen and paper' assessment. The ability to view a digital representation of the as-built model would greatly facilitate identification of structural components and define the scope of field inspection. A surveyor could annotate the as-built building model to indicate damage type and severity for each component. The surveyor could also model damaged components directly using appropriate BIM functions, within existing platforms or tailored software. Augmented reality tools could align the building model display with the actual location, enabling rough measurements of features and rapid and reliable recording of damage. In this mode, damaged components are related directly to their as-built counterparts. The sequence of damage development would not be known.

Guidance for the scope of information needed for a component damage record template is provided in FEMA 306 [4]. The template calls for surveyors to prepare crack maps, sketches, and photographs and associate them with locations in drawings. Component type, location, material test results, assessment of behavior mode, and other comments should also be recorded.

A third method of acquiring a digital as-damaged model is to survey the building using terrestrial laser scanning (static or mobile), terrestrial photogrammetry or video photogrammetry and to use the data to infer as-damaged information with minimal user intervention. Torok et al. [8] have demonstrated techniques for detecting cracks and mapping them in 3D using image recognition techniques; Zhu and Brilakis [19] have achieved similar results using video photogrammetry. Bloch [11] developed and tested a method in which a large data set of potential as-damaged models is pre-calculated from as- 
built models using structural collapse simulation software. Immediately after the earthquake, as-damaged façade building models are derived from laser scans using a technique developed by Zeibak-Shini et al. [7] which also starts from the as-built model. The façade models are used to select the best-fit as-damaged model from the data set. In this mode, both pre-calculated models and façade models must be represented using a BIM schema, and the damage development sequence is known.

\subsection{Use cases for exploitation of as-damaged building models}

To-date, no information technology applications that can use as-damaged building models to support earthquake response have been made operational. Nevertheless, various modes of use can be inferred from the ways in which building models are used in building design and construction. The following applications, although speculative, are rooted in existing and proven technology and provide a useful basis for outlining the information that must be collected.

The first users of as-damaged models after an earthquake would be search and rescue teams. They require information about the building from the as-built model, information about the occupants of the building and their expected locations at the time of the earthquake, and as much information as possible about the physical conditions in the interior of the building. This can be provided on displays in a mobile command post or on portable hardware (tablets, smartphones, heads-up displays, etc.). The data store must support visual display of the location and geometry of components, identification and display of voids, and visual highlighting of the location and nature of potential hazards such as natural gas supply lines. Query of the relationships between damaged components and their counterparts in the as-built model is also needed. The ability to estimate the weights 
of components that must be lifted or of the loads carried by surviving supporting elements can greatly assist the planning of rescue operations. As rescue operations progress and components are revealed, acquisition of new information, whether through modeling or automated scanning, can enable improvement of the accuracy of the models in the scenario proposed by Bloch [11].

Following the first response of S\&R, as-damaged models can support the classification of buildings. Given the presumed dearth of qualified structural engineers in the disaster zone, digital building models could be provided in the internet cloud to structural engineers in remote locations, allowing them to participate in assessment and even to apply their own structural analysis software. In this phase, the models can also be used to design and detail temporary supports with BIM tools. These uses require not only geometry, location, material and member sizes of the remaining components, but also details of the cracking, spalling, bending, delamination and shearing damage sustained by the reinforced concrete structural elements.

Finally, in the longer term, models can support quantity take-off and cost estimation of demolition or of repair works (for insurance and for construction contracting), scheduling and budgeting of repair works (for construction planning) and for recording the new condition of the buildings.

\section{Data modeling of damaged building structures based on IFC schema}

The starting assumption for the use cases described above is that the as-built information model of the building is available. We assume that, regardless of the BIM tool or tools used to generate the model, it will be available in the IFC format. Registered with ISO as 
ISO/PAS 16739, the IFC specification is an open and neutral data schema for BIM [13]. Developed and maintained by buildingSMART, it is a set of definitions describing an internally consistent data representation of building elements. The IFC schema is designed for storage and exchange of building information over the entire life cycle of a building project.

IFC is an object-oriented data schema and is provided in both EXPRESS language [20] and XML formats. As such, it includes a hierarchy of objects that represent a building's components and systems, and a set of relationships that can be defined among those objects. Some objects, such as IfcBuildingElement, are abstract, which means that they serve as parent objects in the inheritance hierarchy (thus allowing specific building object entities like $I f c W a l l, I f c B e a m$ and $I f c D o o r$ to share common property definitions), but they cannot be instanced. For further details, readers are referred to the IFC online documentation [13].

However, the IFC schema cannot be considered complete, and there is a continuing need for new features and enhanced data definitions, especially for specific domains within the construction industry. Enrichment of the IFC schema has been suggested to extend its ability to model elements of road structures [21], bridges [22] and for other specific construction domains. Sacks et al. [23] examined the capability of the IFC $2 \times 3$ schema for modeling precast facades and Eastman et al. [24] proposed the objects and relationships needed to comprehensively model precast concrete structures. Ma et al. [25] suggested extending the IFC $2 \times 3$ schema to support construction cost estimating in China to improve the time consuming and error prone process [26]. Ji et al. [27] extended the IFC-Bridge data schema with the concept of sketch-based parametric bridge design through a family of IfcSketch entities and demonstrated it in two applications to proof the concept. Lin et al. 
[28] added several new property sets to existing IFC entities to enable an application of IFC-based path planning and tested the method on two floor plans. Gokce et al. [29] suggested adding a family of new IfcResource entities to the existing IFC schema to cover detailed cost information. Zhang et al. [30] added three custom property sets to existing IfcProduct entity to enable animation of construction process and demonstrated in a case study. Furthermore, many other researchers and developers [31] have defined model view definitions which specify how domain concepts should be modeled using existing IFC schema elements, as called for in the US National BIM Standard [32].

Although the current IFC schema comprehensively covers a building's as-designed and as-built models, it lacks some of the concepts needed to model as-damaged building elements. Following the RC damage process described in the previous section, the first concept that is lacking is that of the crack. In some cases, it may be sufficient to represent a superficial crack as a feature on the surface of a concrete element; this can be done using the IfcSurfaceFeature entity and its associated relationships and geometry. However, the concept of damage development caused as cracks develop cannot be modeled. After the reinforcing steel in concrete sections reaches its yield limit, plastic hinges develop in building elements, and they separate into segments which have their own distinct geometry, although still connected to one another. If loading continues, elements break into distinct pieces which, although they may move independently, must remain logically associated with the original building element from which they were derived. None of these concepts are represented by any entity or relationship currently defined in the IFC4 schema [13].

Thus, in the remainder of this section, we use the IFC4 schema as the basis for developing the internal object-oriented data schema to serve an arbitrary as-damaged 
building modeling application, but add two new classes. In the penultimate section, we present two scenarios in which as-damaged models might be exchanged between BIM tools using IFC. In the first, only the final geometry is exported, in a case that does not require any addition to the IFC schema. In the second, the full damage history can be exported, but this requires extension of the IFC schema.

\subsection{An IFC data schema extension for as-damaged building models.}

The kernel of the proposed data schema extension is shown in an EXPRESS-G diagram in Figure 1. The IfcBuildingElement class represents the physical parts of the building as it does in IFC [13]. In this context, the instances of its child entities (IfcBeam, IfcColumn, etc.) together represent the as-built state of the building.

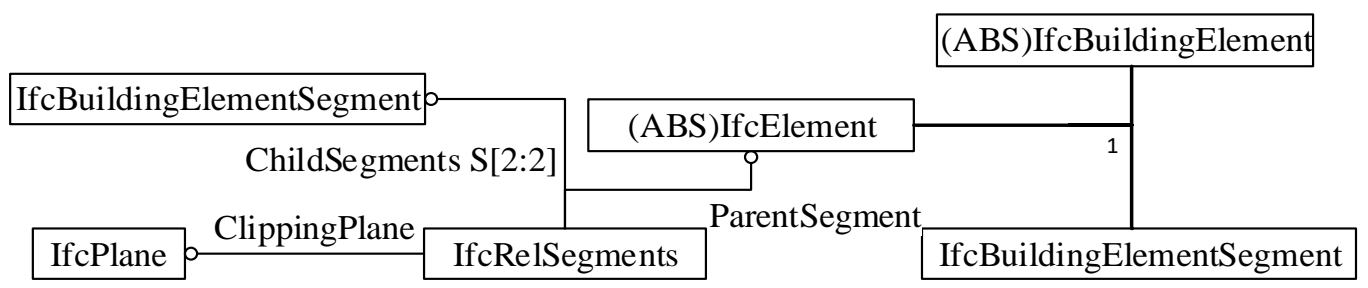

Figure 1 Kernel of the as-damaged schema in Express-G format. Note that the EXPRESSG nomenclature '(ABS)' denotes an abstract class, i.e. a class that is not instantiated.

The new IfcBuildingElementSegment ${ }^{4}$ class models the new geometry of a damaged part of an IfcBuildingElement. Like the IfcBuildingElement, it is a subtype of IfcElement, from which it inherits object placement and shape representation. At least two IfcBuildingElementSegment entities are generated for each IfcBuildingElement if it sustains a crack or cracks that propagate sufficiently to break it into distinct parts. The crack may be in any direction and it need not penetrate the whole depth of the section, but it does allow

\footnotetext{
${ }^{4}$ The IfcBuildingElementSegment represents a detached part of a building element. A more specific name might be IfcDamagedBuildingElementSegment. However, due the length of this name we preferred the shorter version.
} 
displacement of the two parts of the original RC element relative to their parent. Similarly, if a resulting child IfcBuildingElementSegment has been split, two additional IfcBuildingElementSegment instances are generated. Splitting can be repeated recursively, thus building a binary tree that contains the full set of segments into which the RC element has been segmented (the process is described in detail in section 3.3 below). A segment that has itself been segmented has its status field set to SEGMENTED, which marks it as a virtual container of the further resulting new segments; if a segment has been destroyed or cannot be identified, the value is set to MISSING; if a segment exists and does not need itself to be segmented the value is EXISTING. Both MISSING and EXISTING segments are leaf nodes on the binary tree. The EXPRESS specification of the IfcBuildingElementSegment is as follows:

\section{ENTITY IfcBuildingElementSegment SUBTYPE OF IfcElement; Status :IfcSegmentStatusEnum; INVERSE \\ IsASegmentOf $\quad$ : SET [0:1] OF IfcRelSegments FOR ParentSegment; Is SegmentedBy : SET [0:2] OF IfcRelSegments FOR ChildSegments; \\ END_ENTITY;}

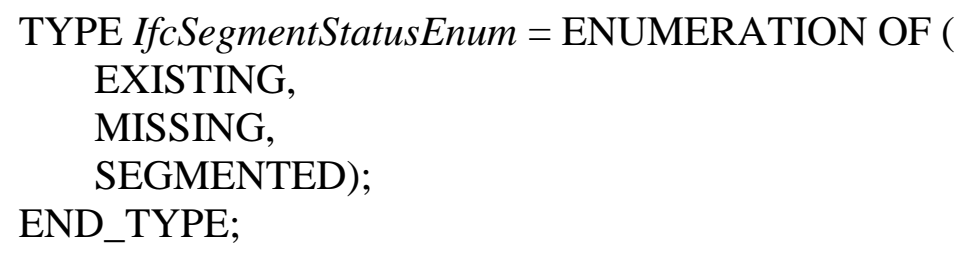

The segmentation itself is modeled as an objectified relationship by the new IfcRelSegments relationship. IfcRelSegments contains pointers to the 'parent' segment that existed before the split and to the two resulting 'child' segments (the parent segment is either an IfcBuidlingElementSegment or, if this is the first split of the building element, a subtype of IfcBuildingElement). The EXPRESS specification is as follows: 


\author{
ENTITY IfcRelSegments \\ SUBTYPE OF IfcRelDecomposes; \\ ParentSegment : IfcElement; (NOTE: this will always be either an \\ IfcBuildingElementSegment or a subtype of \\ IfcBuildingElement); \\ ChildSegments $\quad$ : SET [2:2] OF IfcBuildingElementSegment; \\ ClippingPlane :IfcPlane; \\ CrackType :IfcCrackTypeEnum; \\ END_ENTITY; \\ TYPE IfcCrackTypeEnum = ENUMERATION OF ( \\ DELAMINATION_CRACK, \\ BENDING_CRACK, \\ SHEARING_CRACK); \\ END_TYPE;
}

\title{
3.2. Modeling the geometry of damaged RC elements.
}

The as-built building model is assumed to contain the semantic information of the elements. Given the direct relationship between each IfcBuildingElement and the corresponding IfcBuildingElementSegment, the alphanumeric information of the segments (material type and properties, element type classification, reference to spatial structures, etc.) can be derived directly (the relationship can be seen in Figure 1). Therefore, the IfcBuildingElementSegment deals primarily with the changed shape of the segments of the original components. Collecting and recording this information is the key task in the postearthquake survey.

The geometry definitions of IfcBuildingElementSegment are inherited from IfcElement and are given by the IfcProductDefinitionShape and IfcLocalPlacement, allowing multiple geometric representations, such as Body SweptSolid Geometry, Body Brep Geometry, Body CSG Geometry, etc. Among those representations, the Body Clipping Geometry is considered the most suitable, because the resulting segments are consistent with the damage modes. Segments of both longitudinal RC elements (such as beams, columns and spandrels) 
and plate RC elements (such as walls and slabs) can be defined using the SweptSolid geometry with additional clippings applied. The clipping process is defined by IfcHalfSpaceSolid which uses IfcPlane as the base surface, as is shown in Figure 2. Note that the clipping plane may have arbitrary position and direction; it need not be perpendicular to the major axis of the $\mathrm{RC}$ element.

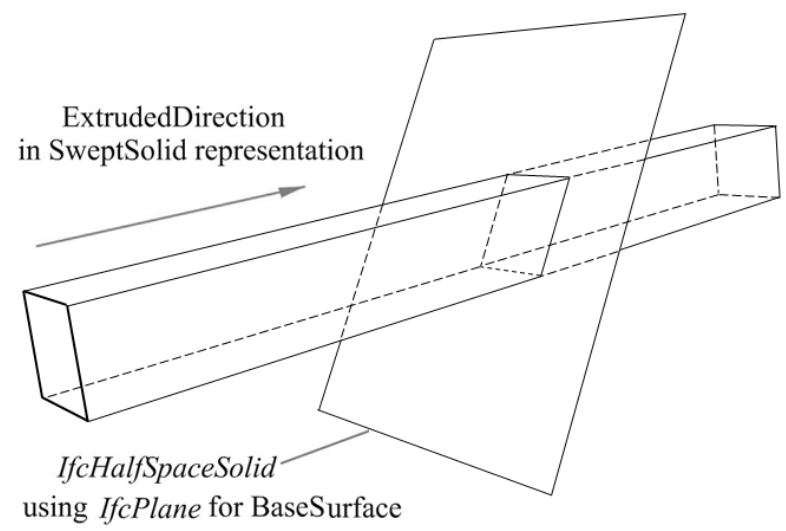

Figure 2 Illustration of body clipping in IFC schema.

\subsection{Modeling of the propagative damage process.}

According to the identified damage modes, a crack is an intermediary of the propagative damage process. The cracking process is modeled by clipping the building element at a clipping plane, dividing it in two. In this way, the final geometry of the RC element is represented by a binary tree, and the process of damage itself is stored explicitly by the data structure. The damage-recording process is to identify the cracks on a particular building element, apply the crack object (IfcRelSegments) and a clipping plane to the first crack selected, subdivide the element into two resulting segments, translate and/or rotate the segments if they have moved or broken away from the parent element, and then repeat recursively for each new segment and for all the original parent segments, until all damage has been recorded. 
Each clipping plane results in two segments and $n$ clipping planes split the element into $n+1$ segments. This process follows the Taoist principle stated by the ancient Chinese philosopher Laozi: "one procreates two, two procreates three, and three procreates everything". The binary tree structure is defined by the 1:1 ParentSegment and 1:2 ChildSegment references of the IfcRelSegments instances (shown in Figure 1 and in the EXPRESS specification above), so that the iterative segmenting process is made explicit and is available for reconstruction.

\section{Representation examples of as-damaged RC elements and frames}

Earthquake damage to reinforced concrete structures was examined in extensive online photographic records, primarily from the Earthquake Engineering Research Institute (EERI) databases [33]. The modeling examples in this section are based on two structures damaged in the earthquakes on $11^{\text {th }}$ March 2011, Honshu, Japan and on $12^{\text {th }}$ May 2008, Wenchuan, China, respectively.

The as-damaged building models were compiled using a computer program developed for this research using the schema defined in section 3. The software was developed in Microsoft Visual Studio $2012 \mathrm{C}++$ [34] and used a series of $3^{\text {rd }}$ party libraries, including Boost 1.46.1 [35] for shared pointers and threading, Eigen 3.0 [36] as the matrix backend for SSE (Streaming SIMD Extensions) optimized math and Visualization ToolKit (VTK) 5.6.1 [37] for rendering and visualization.

Figure 3 shows the workflow followed in using the program. The process begins with selection of an as-built building element and instantiation of a corresponding segment. Examining the photographic evidence, the user determined the relative location and 
orientation of the first crack. The software applied the cutting plane and instantiated two resulting segments. The user then determined the translation and rotation of the first new segment and entered the data, viewing the result to confirm. This process was continued recursively for all new segments and for each building element until the user was satisfied that the resulting model corresponded to the as-damaged state.

For simplicity of implementation, the shape of each building segment was approximated as a bounding box oriented parallel to the axes of its local reference frame, and the origin of its local reference frame was defined at the box's centroid, as is shown in Figure 4. Similarly, the clipping plane was constrained to be perpendicular to the principal axis of the segment. The three segmenting under these conditions are shown in Table 2. Note that these limitations are not mandatory, they simply facilitated implementation of the demonstration computer program designed to illustrate the data structure and the evaluation process. 


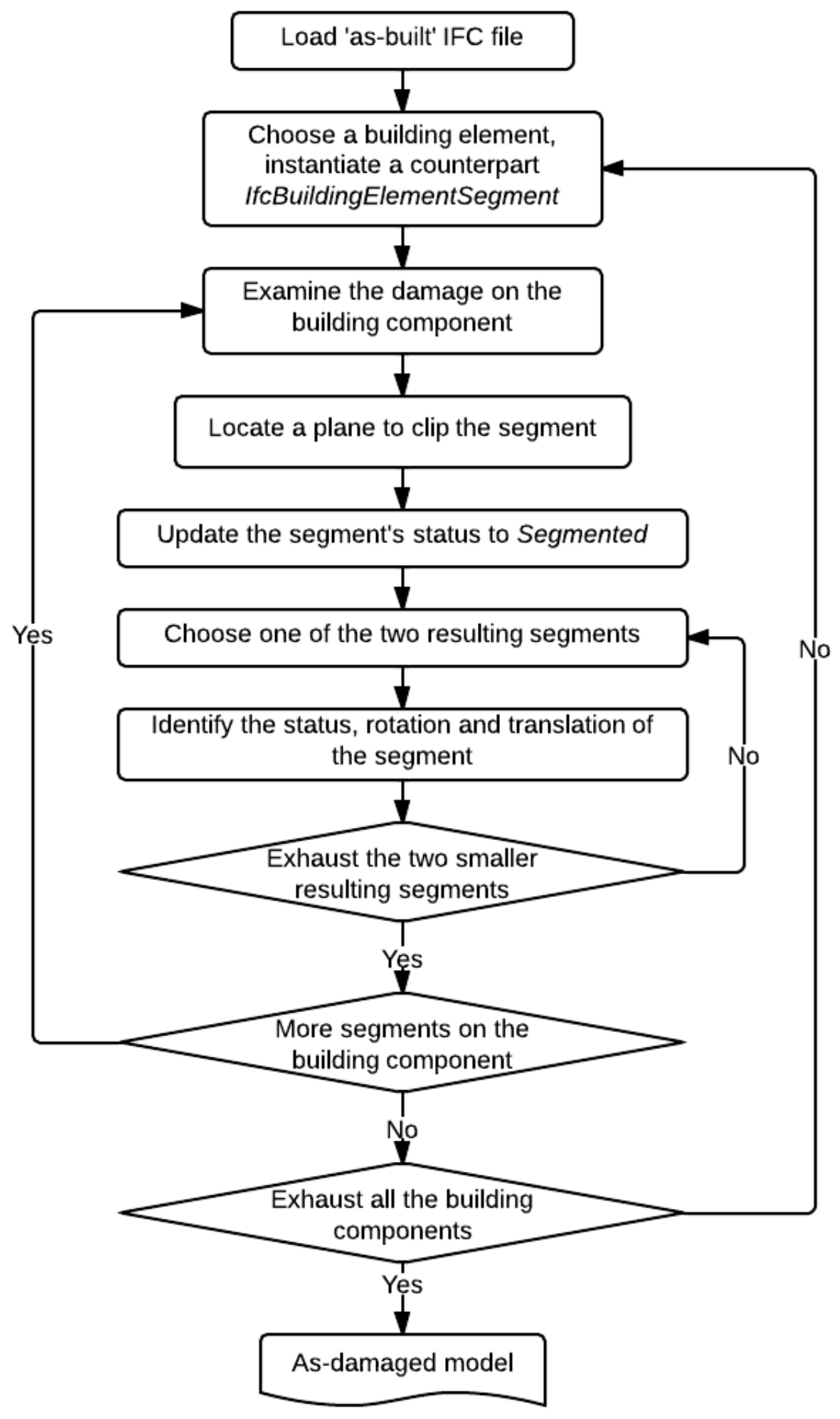

Figure 3 Workflow for generating as-damaged model. 


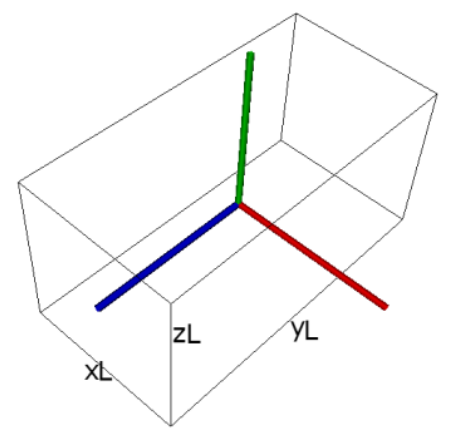

Figure 4 Illustration of the axis-aligned bounding box representation Table 2 Cases of three typical clipping planes

\begin{tabular}{|l|c|c|c|}
\hline Parameter & Clip in YZ plane & Clip in XZ plane & Clip in XY plane \\
\hline Clipping plane & $a x+w=0$ & $b y+w=0$ & $c z+w=0$ \\
\hline Range of segment 1 & $(-x L / 2,-\mathrm{w} / \mathrm{a})$ & $(-y L / 2,-\mathrm{w} / b)$ & $(-z L / 2,-\mathrm{w} / c)$ \\
\hline Range of segment 2 & $(-\mathrm{w} / \mathrm{a}, x L / 2)$ & $(-\mathrm{w} / b, y L / 2)$ & $(-\mathrm{w} / c, z L / 2)$ \\
\hline $\begin{array}{l}\text { Centroid of segment 1 } \\
\text { relative to its parent's }\end{array}$ & $\left(-\frac{a \cdot x L+2 w}{4 \mathrm{a}}, 0,0\right)$ & $\left(0,-\frac{b \cdot y L+2 w}{4 \mathrm{~b}}, 0\right)$ & $\left(0,-\frac{c \cdot z L+2 w}{4 \mathrm{c}}, 0\right)$ \\
centroid & $\left(\frac{a \cdot x L-2 w}{4 \mathrm{a}}, 0,0\right)$ & $\left(0, \frac{b \cdot y L-2 w}{4 \mathrm{~b}}, 0\right)$ & $\left(0, \frac{c \cdot z L-2 w}{4 \mathrm{c}}, 0\right)$ \\
\hline $\begin{array}{l}\text { Centroid of segment 2 } \\
\text { relative to its parent's } \\
\text { centroid }\end{array}$ & & & \\
\hline
\end{tabular}

\subsection{Example of damaged column}

The RC column shown in Figure 5 (a) was damaged in the Honshu, Japan earthquake on $11^{\text {th }}$ March 2011. The as-damaged model created using the experimental software is shown 
in Figure 5 (b) for comparison. The geometry information of the first IfcBuildingElementSegment which represents the column as-built geometry is given in Table 3 and shown in Figure 6 (a). Figure 6 as a whole illustrates the process of progressively identifying the clipping plane and the displacement of resulting segments and Figure 7 shows the corresponding development of data model instances. By examine the photo, clipping planes and relative movements of the resulting segments are identified in Table 4 and Table 5 respectively.

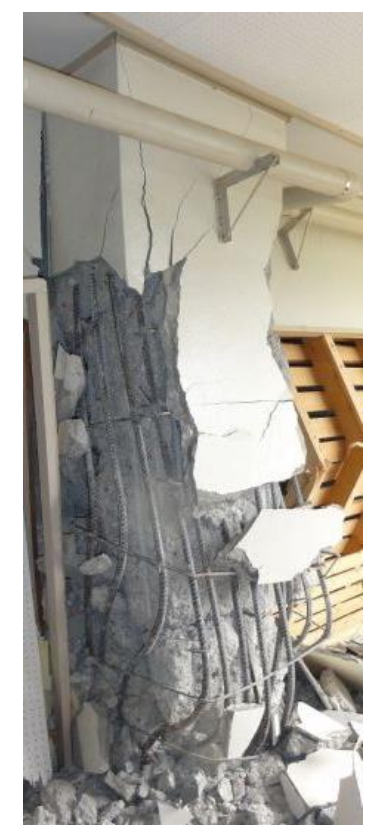

(a)

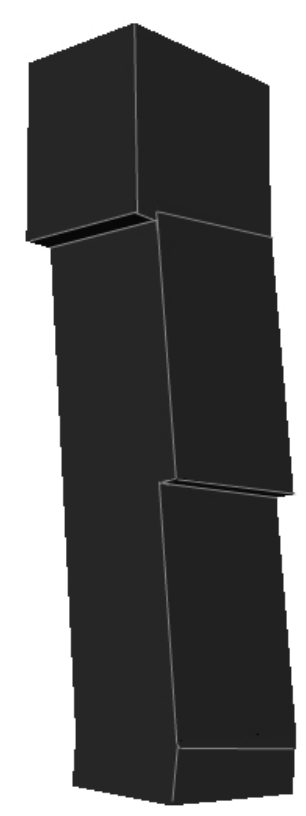

(b)

Figure 5. Photo and corresponding as-damaged model of damaged column.

Table 3. Geometry of building components in the damaged column example.

\begin{tabular}{|c|c|c|c|c|c|c|c|}
\hline \multirow{2}{*}{ Element Type } & \multirow{2}{*}{ ID } & \multicolumn{3}{|c|}{ Centroid Location } & \multicolumn{3}{c|}{ Dimensions } \\
\cline { 3 - 8 } & & $\mathrm{x}$ & $\mathrm{y}$ & $\mathrm{z}$ & $\mathrm{x}$ & $\mathrm{y}$ & $\mathrm{z}$ \\
\hline Column & 0 & 0 & 0 & 0 & 350 & 1800 & 500 \\
\hline
\end{tabular}


Table 4. Identified clipping planes on segments in the damaged column example.

\begin{tabular}{|c|c|c|c|c|c|}
\hline \multirow{2}{*}{ Illustration in Figure 6 } & \multirow{2}{*}{ ID } & \multicolumn{4}{|c|}{ Coefficients of clipping plane } \\
\cline { 2 - 6 } & & $\mathrm{x}$ & $\mathrm{y}$ & $\mathrm{z}$ & w/side length \\
\hline \multirow{2}{*}{ (b) } & 0 & 0 & 1 & 0 & 0.25 \\
\cline { 2 - 6 } & 1 & 0 & 0 & 1 & 0.35 \\
\hline \multirow{2}{*}{ (d) } & 3 & 0 & 1 & 0 & 0.02 \\
\hline & 5 & 1 & 0 & 0 & 0.35 \\
\hline (f) & 7 & 0 & 1 & 0 & -0.3 \\
\hline
\end{tabular}

Table 5. Relative displacement of segments in the damaged column example.

\begin{tabular}{|c|c|c|c|c|c|c|c|c|c|}
\hline \multirow{2}{*}{$\begin{array}{c}\text { Illustration in } \\
\text { Figure } 6\end{array}$} & \multirow{2}{*}{$\begin{array}{c}\text { Segment } \\
\text { GUID }\end{array}$} & \multicolumn{3}{|c|}{$\begin{array}{l}\text { Coefficients of } \\
\text { rotation axis }\end{array}$} & \multirow{2}{*}{$\begin{array}{c}\text { Relative } \\
\text { rotation angle }\end{array}$} & \multicolumn{3}{|c|}{$\begin{array}{l}\text { Relative } \\
\text { translation }\end{array}$} & \multirow{2}{*}{$\begin{array}{l}\text { Fall } \\
\text { off }\end{array}$} \\
\hline & & $\mathrm{x}$ & $\mathrm{y}$ & $\mathrm{z}$ & & $\mathrm{x}$ & $\mathrm{y}$ & $\mathrm{z}$ & \\
\hline \multirow{2}{*}{ (c) } & 4 & 0 & 0 & 0 & 0 & 0 & 0 & 0 & 0 \\
\hline & 3 & 0 & 0 & 1 & 5 & 65 & 30 & 0 & 1 \\
\hline (e) & 8 & 0 & 0 & 0 & 0 & 0 & 0 & 0 & 0 \\
\hline (g) & 9 & 0 & 0 & 1 & -10 & -15 & 30 & 0 & 1 \\
\hline
\end{tabular}




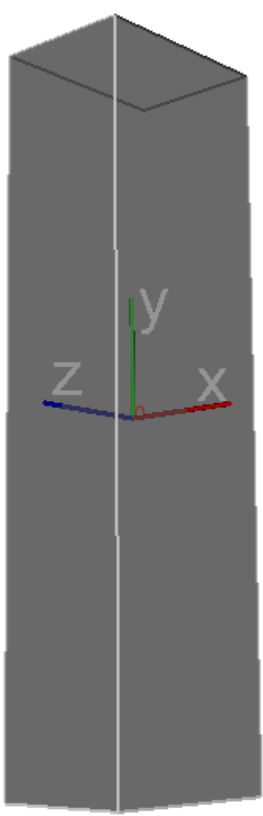

(a)

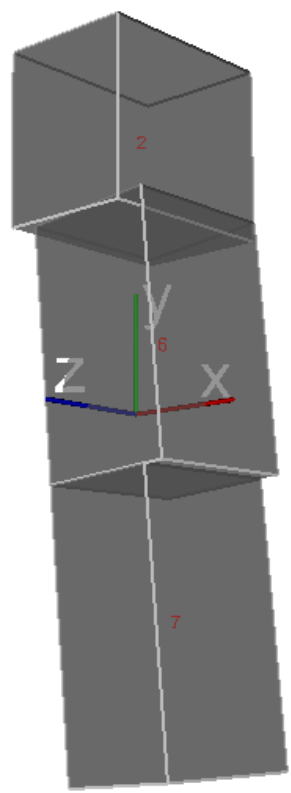

(e)

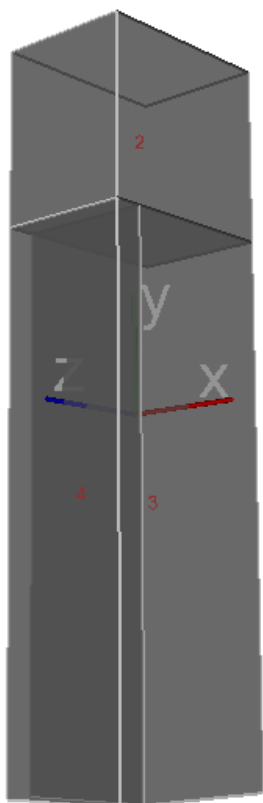

(b)

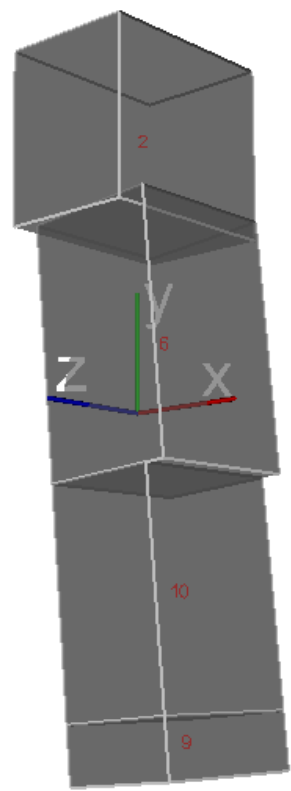

(f)

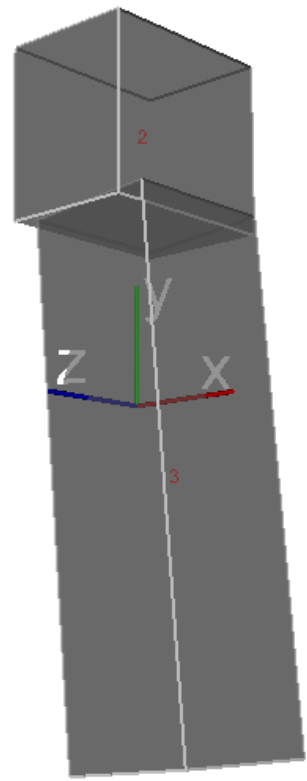

(c)

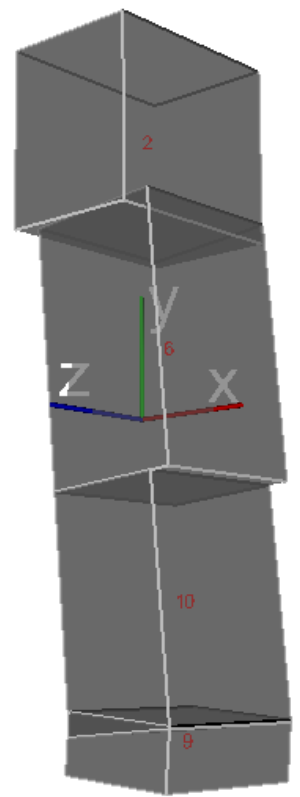

$(\mathrm{g})$

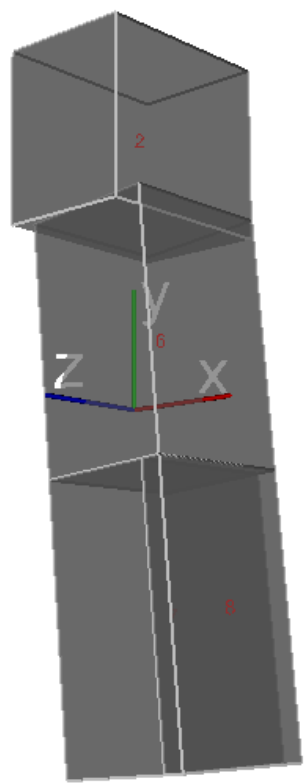

(d)

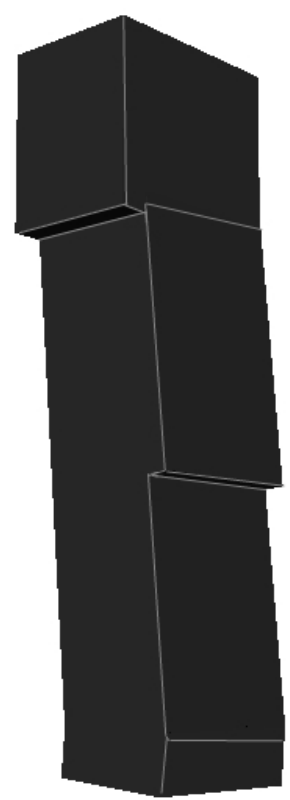

(h)

Figure 6. The progressive damage process in the damaged column case. 


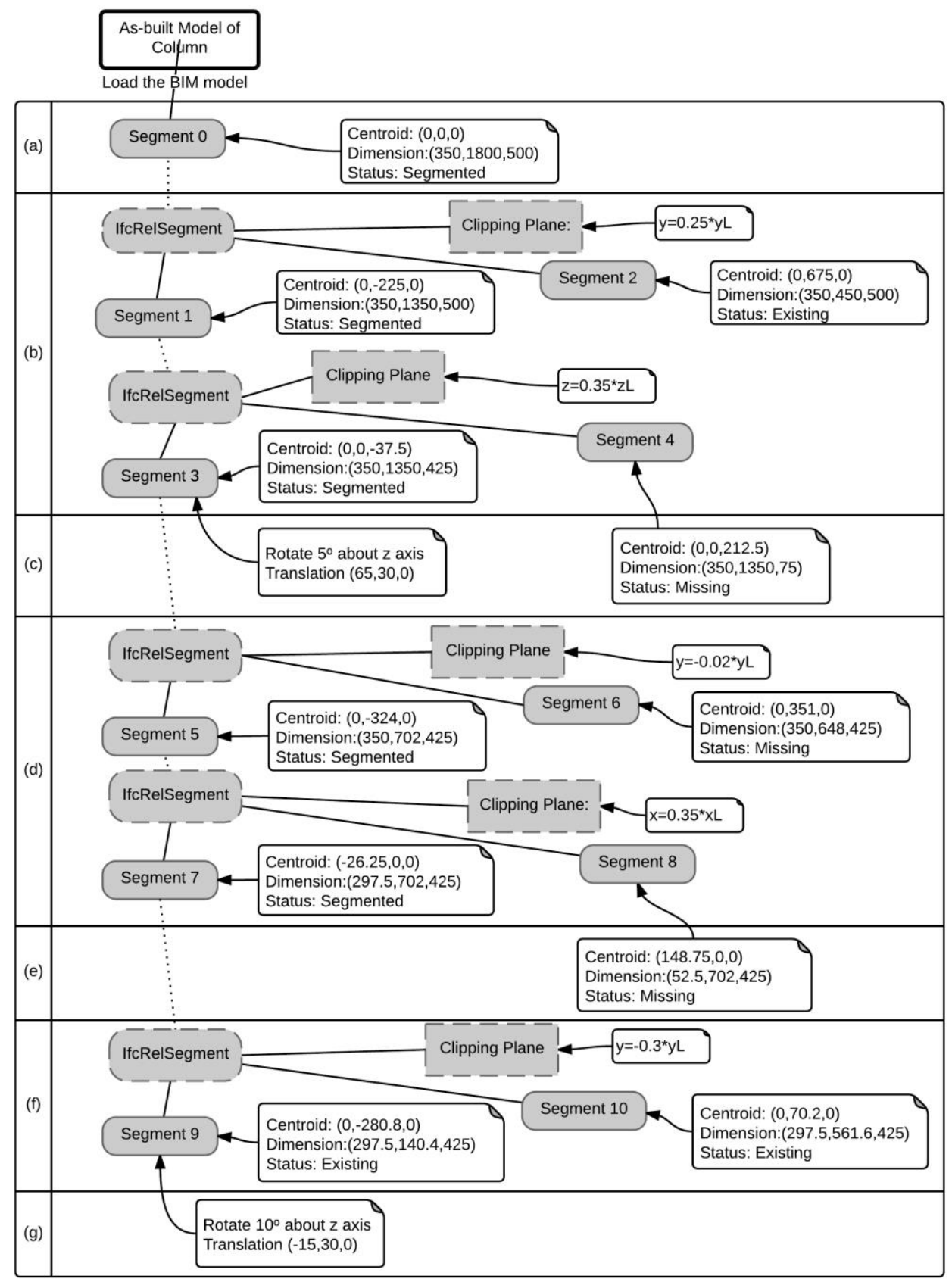

Figure 7. Process of model instantiation for the as-damaged column case. The sequence in the left-hand column corresponds to the sequence of definition from Figure 6.

In addition, part of the STEP Part 21 exchange file is illustrated in Figure 8. The file is shown parsed using IfcQuickBrowser software [35]. Line \#453 shows the IfcBuilidngElementSegment entity of Segment 1 (refer to the Figure 7). It is involved in two 
relationships which are shown in the bottom panel. The first relationship, i.e., \#445 IFCRELSEGMENTS, shows that Segment 1 is decomposed from the original column, which is represented in \#264 IFCCOLUMN. The other relationship, i.e., \#465 IFCRELSEGMENTS, shows that Segment 1 is further decomposed into two segments i.e., Segment 3 and Segment 4 which are represented in lines \#474 and \# 472 respectively. Note that Segment 1 and Segment 3 are further cracked and that Segment 4 falls off due to delamination, so the status of entities in line \#453, \#473 and \#472 are SEGMENTED, SEGMENTED and MISSING respectively. In addition, the two relationships (lines \#445 and \#465) also reflect the damage types as DELAMINATION_CRACK and SHEARING_CRACK.

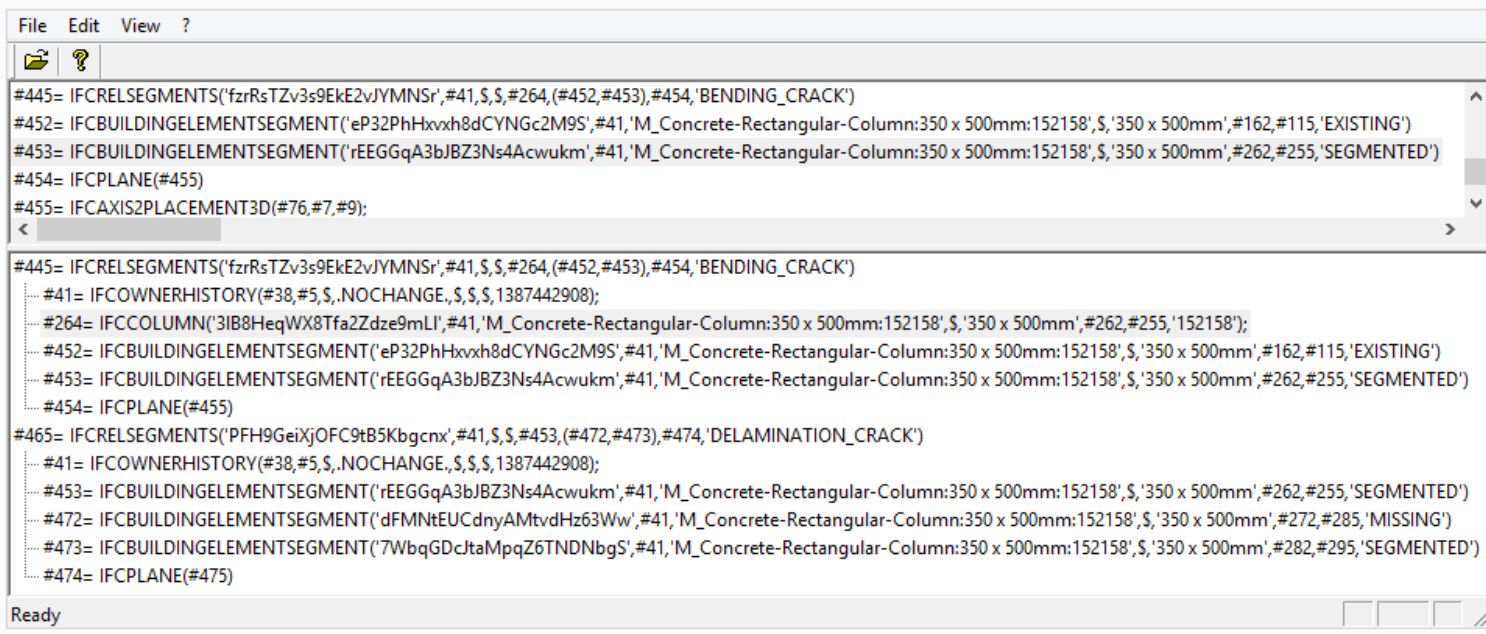

Figure 8. Part of the STEP Part 21 file for the damaged column, shown parsed using IfcQuickBrowser software [35].

\subsection{Example of damaged frame}

The RC frame in this case was damaged in an earthquake on $12^{\text {th }}$ May 2008, in Wenchuan, China. The geometry of the original building elements is listed in Table 6 . Figure 9 (a) is a photograph of the damaged frame. The following parts of Figure 9 show 
how sequential damage was recorded by progressively identifying the clipping plane and relative movement of corresponding segments. Table 6 is the as-built geometry. By examine the photo, clipping planes and relative movements of the resulting segments are identified in Table 7 and Table 8 respectively.

Table 6. Geometry of building components

\begin{tabular}{|c|c|c|c|c|c|c|c|}
\hline \multirow{2}{*}{$\begin{array}{c}\text { Element } \\
\text { Type }\end{array}$} & \multirow{2}{*}{$\begin{array}{c}\text { Element } \\
\text { ID }\end{array}$} & \multicolumn{3}{|c|}{ Centroid } & \multicolumn{3}{|c|}{ Length along each axis } \\
\hline & & $\mathrm{X}$ & $\mathrm{y}$ & Z & $\mathrm{X}$ & $\mathrm{y}$ & $\mathrm{Z}$ \\
\hline Wall & 0 & 0 & 1200 & -3700 & 4800 & 2400 & 200 \\
\hline Wall & 1 & 0 & 1200 & 3700 & 4800 & 2400 & 200 \\
\hline Beam & 2 & 0 & 2600 & -3700 & 4800 & 400 & 200 \\
\hline Beam & 3 & 0 & 2600 & 3700 & 4800 & 400 & 200 \\
\hline Slab & 4 & 0 & 2900 & 0 & 4800 & 200 & 7600 \\
\hline Beam & 5 & 2600 & 2700 & 0 & 400 & 600 & 7600 \\
\hline Beam & 6 & -2600 & 2700 & 0 & 400 & 600 & 7600 \\
\hline Column & 7 & 2600 & 1200 & -3400 & 400 & 2400 & 800 \\
\hline Column & 8 & 2600 & 1200 & 3400 & 400 & 2400 & 800 \\
\hline Column & 9 & -2600 & 1200 & -3400 & 400 & 2400 & 800 \\
\hline Column & 10 & -2600 & 1200 & 3400 & 400 & 2400 & 800 \\
\hline
\end{tabular}

Table 7 Identified clipping planes on the progressively identified segments

\begin{tabular}{|c|c|c|c|c|c|}
\hline \multirow{2}{*}{ Illustration in Figure 9 } & \multirow{2}{*}{ Segment GUID } & \multicolumn{4}{|c|}{ Coefficients of clipping plane } \\
\cline { 3 - 6 } & & $\mathrm{x}$ & $\mathrm{y}$ & $\mathrm{z}$ & w/side length \\
\hline \multirow{2}{*}{ (c) } & 4 & 0 & 0 & 1 & 0 \\
\cline { 2 - 6 } & 5 & 0 & 0 & 1 & 0 \\
\hline
\end{tabular}




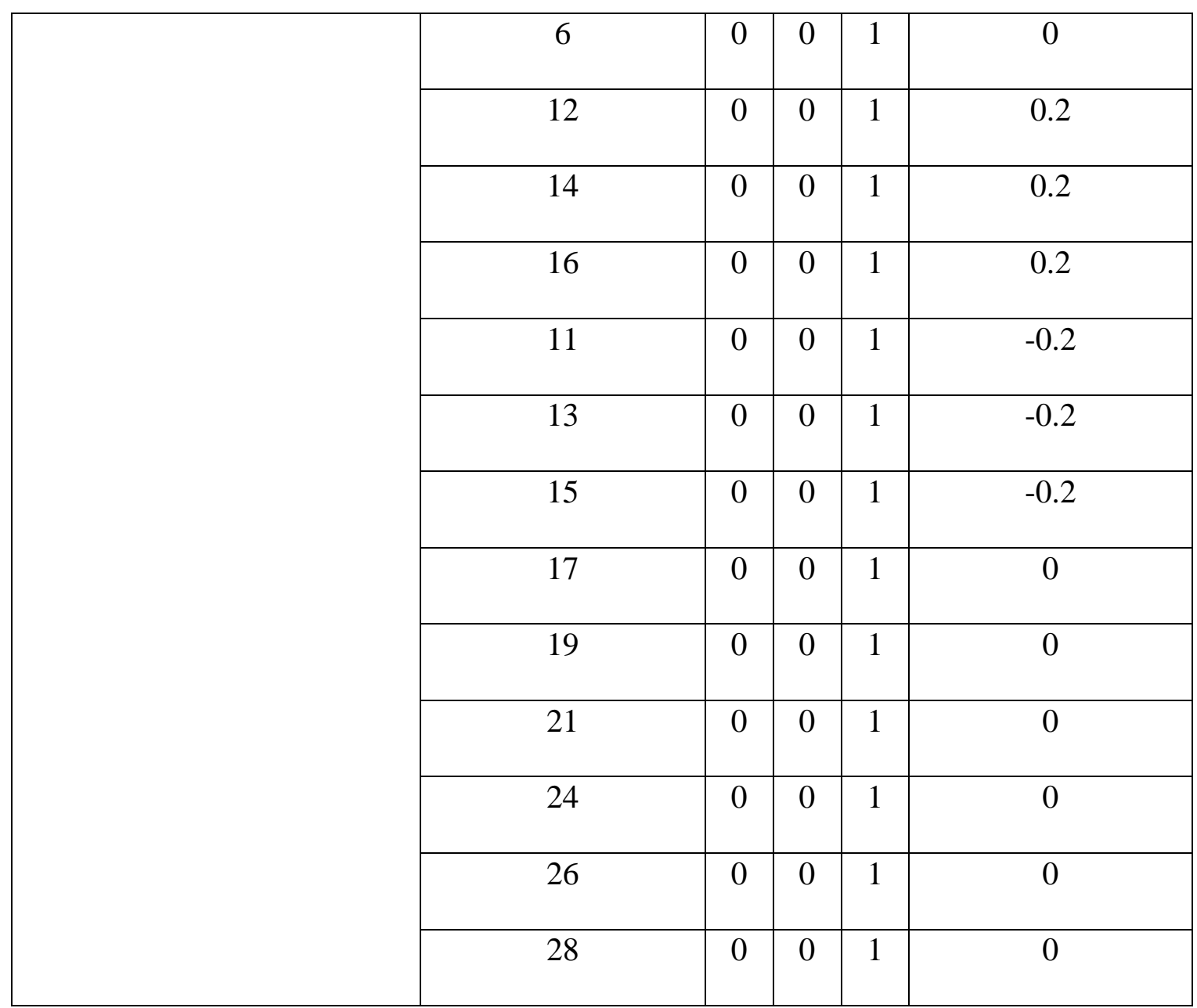

Table 8 Relative movement of segments

\begin{tabular}{|c|c|c|c|c|c|c|c|c|c|}
\hline \multirow{2}{*}{$\begin{array}{c}\text { Illustration in } \\
\text { Figure } 9\end{array}$} & \multirow{2}{*}{$\begin{array}{c}\text { Segment } \\
\text { ID }\end{array}$} & \multicolumn{3}{|c|}{$\begin{array}{c}\text { Coefficients of } \\
\text { rotation axis }\end{array}$} & \multirow{2}{*}{$\begin{array}{c}\text { Relative } \\
\text { rotation angle }\end{array}$} & \multicolumn{3}{|c|}{$\begin{array}{l}\text { Relative } \\
\text { translation }\end{array}$} & \multirow{2}{*}{$\begin{array}{l}\text { Fall } \\
\text { off }\end{array}$} \\
\hline & & $\mathrm{x}$ & $\mathrm{y}$ & $\mathrm{Z}$ & & $\mathrm{x}$ & $\mathrm{y}$ & $\mathrm{Z}$ & \\
\hline \multirow{3}{*}{ (d) } & 30 & 1 & 0 & 0 & -10 & 0 & $\begin{array}{c}- \\
120\end{array}$ & 25 & 1 \\
\hline & 32 & 1 & 0 & 0 & -10 & 0 & $\begin{array}{c}- \\
120\end{array}$ & 30 & 1 \\
\hline & 34 & 1 & 0 & 0 & -10 & 0 & 120 & 30 & 1 \\
\hline
\end{tabular}




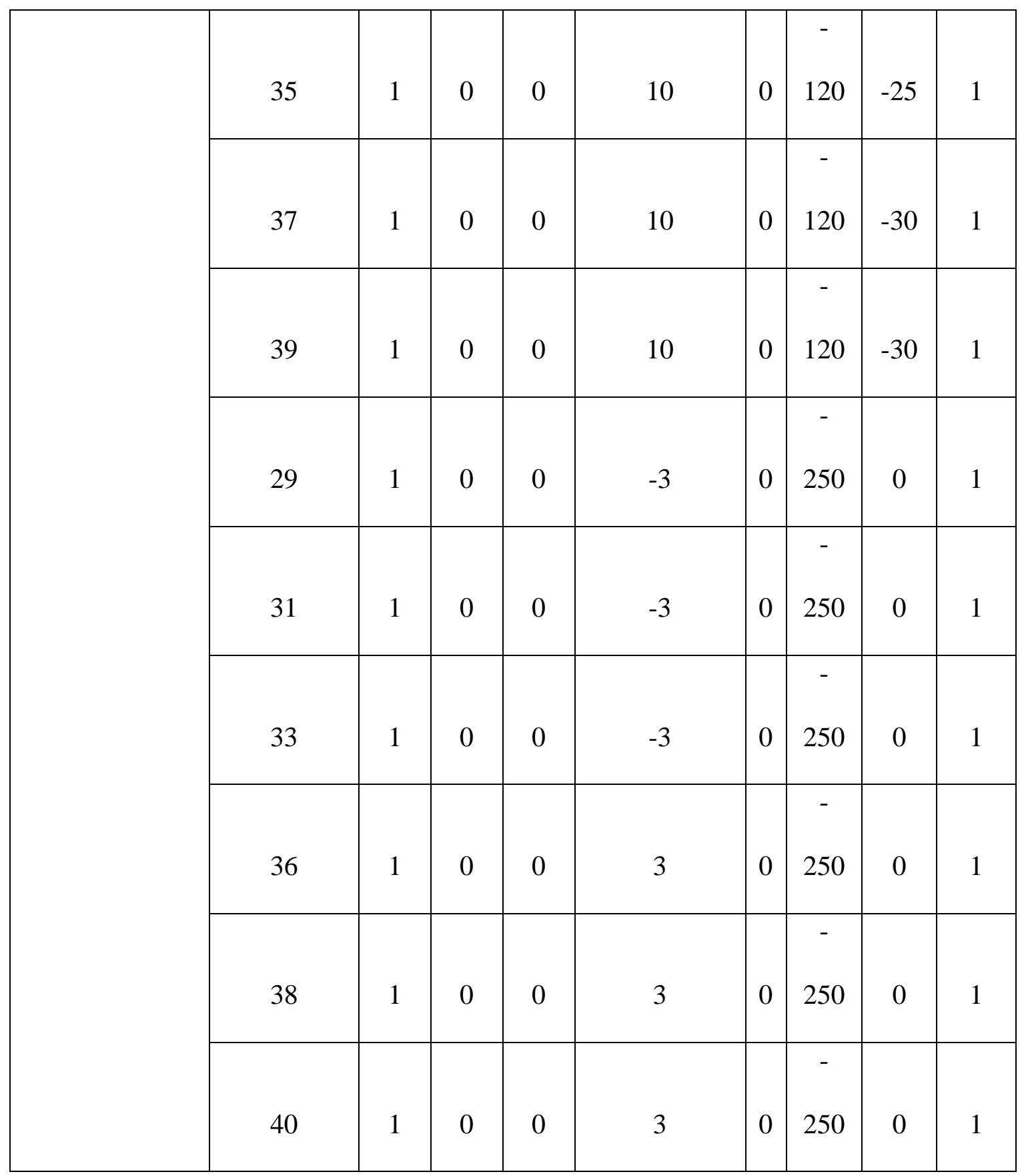




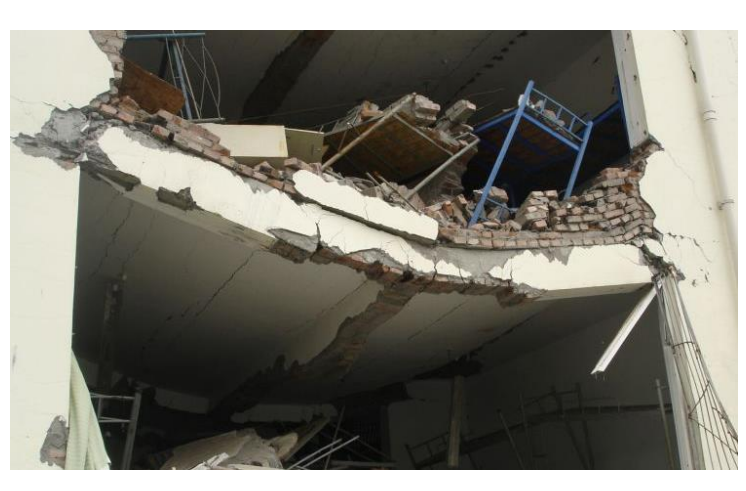

(a)

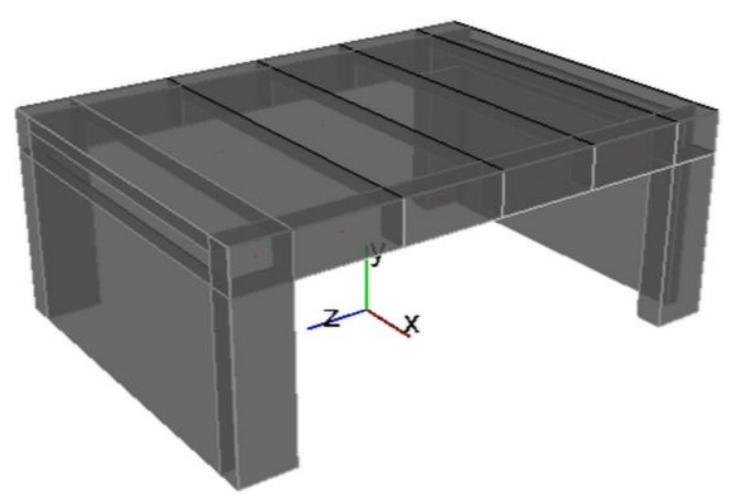

(c)

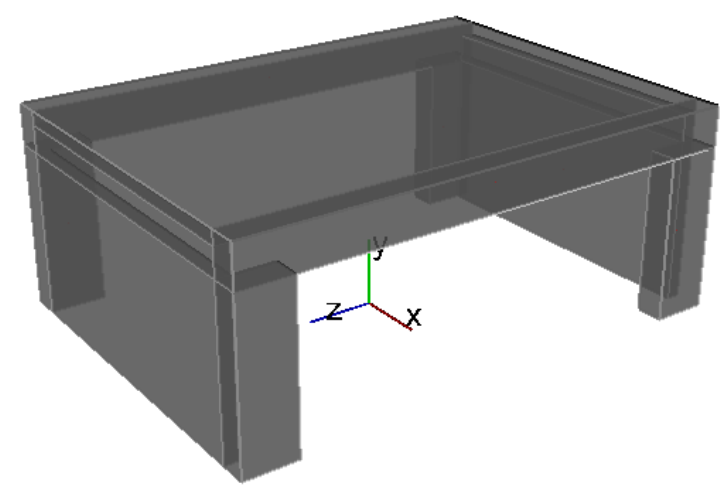

(b)

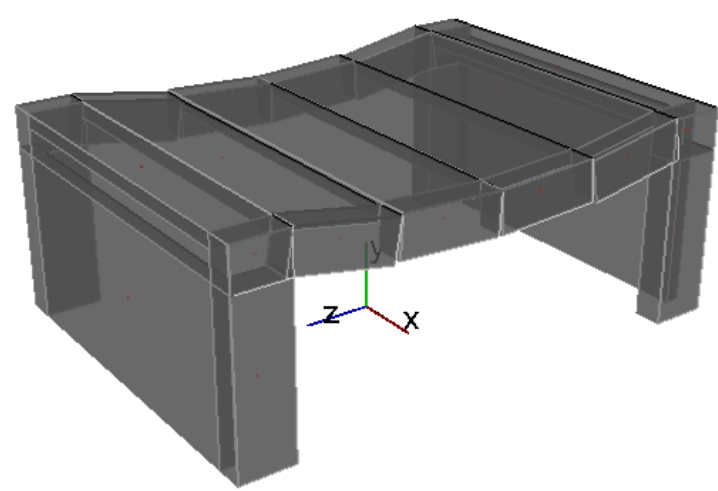

(d)

Figure 9. The progressive process of damage recording for the damaged frame case

\section{Representing and Exchanging Models of Damaged Buildings}

\subsection{Representing damage using the proposed schema extension}

With the addition of the proposed IfcBuildingElementSegment entity and the IfcRelSegments relationship to IFC4, RC elements with any of the damage modes described in Section 2.1 can be represented. Each of them has been successfully done in the examples presented in Section 4. The approaches can be summarized as follows:

1) Surface cracking 
The IfcSurfaceFeature entity in IFC4 schema is used to model textures or small voids or volumes on an element's surface. This entity can be used to model surface cracks on an IfcBuildingElement or an IfcBuildingElementSegment. Its instances can refer to geometry that is two- or three-dimensional and they are related to the host entities using aggregation relationships as defined in the IFC specifications [13].

2) Spalling and delamination

In this case the modeling strategy depends on the relative size and shape of the voids created and the degree of precision required in the model. In general, spalling should be modeled using IfcSurfaceFeature entities as described above, and delamination should be modeled using IfcBuildingElementSegment entities with the status property set to MISSING, as shown in the example in Section 4.1.

3) Bending and buckling

The resulting non-linear shapes of components that have bent or buckled to the point where cracks have propagated through the cross-section are modeled using IfcBuildingElementSegment entities and IfcRelSegments relationships. The orientation of each IfcBuildingElementSegment is given by IfcLocalPlacement through IfcAxis2Placement $3 D . P$ in its own local reference frame. The primary mechanism is rotation of the segments and the accuracy of the geometric representation depends on the number of segments decomposed from the building component, i.e. on the modeling precision.

4) Shearing and breaking 
Shearing or breaking can be represented as the movement of distinct IfcBuildingElementSegment entities relative to the original element and tone another. Translation is the primary mechanism of movement of the segments from their original locations. The translation of each segment is also given by IfcLocalPlacement, but through IfcPlacement.Location.

\subsection{Exchanging models with damage using IFC4}

Although the proposed schema extension is primarily intended for information exchange between BIM applications, it can also be used as the basis for internal representation of asdamaged buildings and their components within BIM applications. The latter two use-cases described in Section 2.2 both rely on the ability to store the data in BIM applications. When the data is exported, however, the contents of the exchange file should be appropriate for the receiving application. Here there are two possibilities:

1) If the receiving application is capable of representing the damage according to the schema extension, the exchange file should include the complete binary tree which represents not only the final state but also the process of damage and the development of cracks.

2) If the receiving application is not capable of representing the damage according to the schema extension, the exchange file may contain only the original components and the EXISTING segments. In this case, only the final damage state will be exchanged.

Both forms require the original as-built building elements to provide the element crosssection or other shape geometry and the various non-geometric properties. Figure 10 shows 
the second export case, where the exported IFC file contains only the leaf-nodes of the binary tree.

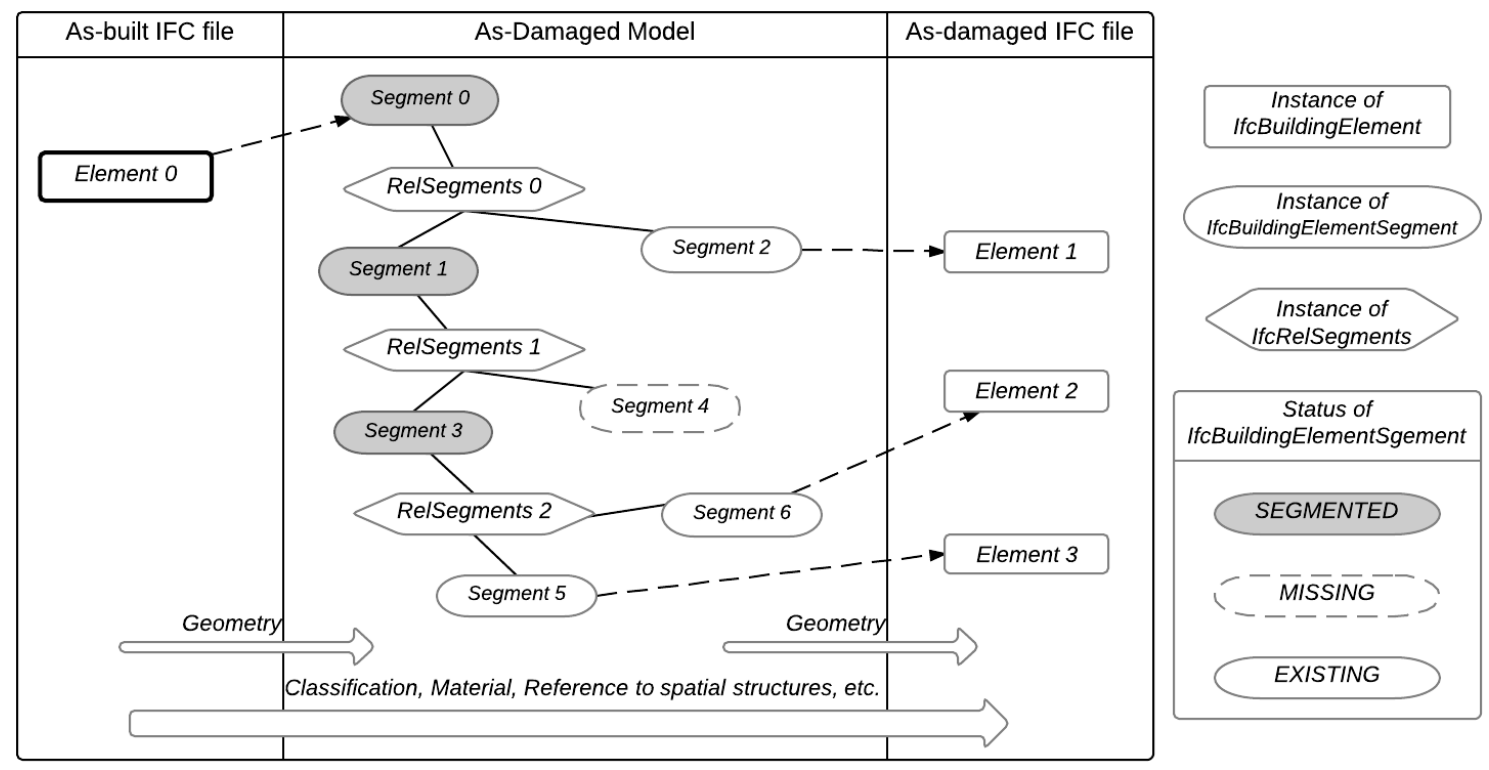

Figure 10. Import and partial 'final damage state only' export of as-damaged building model data.

Whereas the internal data schema of any BIM application is subject to the sole discretion of its vendor, the IFC schema requires broad consensus. Ideally, the two new entities (IfcBuildingElementSegment and IfcRelSegments) would be added to the core IFC schema as a 'Damaged Building' extension. However, pending such extension, both the full damage case and the final state only case can be exchanged using the existing IFC4 schema and an appropriate model view definition (MVD [38]). The MVD would need to apply business rules to substitute an appropriate subtype of IfcBuildingElementSegment for each IfcBuildingElementSegment instance, and an IfcConnectsWithRealizingElements as a substitute for each IfcRelSegments instance. In both cases appropriate values for Name, Description and ObjectType properties could be defined to specialize the substituted classes. 


\section{Conclusion}

Motivated by the need to represent the condition of RC buildings for post-earthquake search and rescue and damage assessment, as expressed in the use-cases outlined, this research proposes an as-damaged data model based on the IFC schema. The data model represents the typical damage modes of RC structures. It contains two new object classes: IfcBuildingElementSegment models the parts of damaged elements using swept solid geometry and clipping planes; and IfcRelSegments, which models the objectified relationships between original building elements, clipping planes and their resultant segments. A significant contribution inherent in the proposed schema kernel is that the sequence of damage and the resulting geometry is recorded explicitly as a binary tree of successively cracked and split segments.

To test and to illustrate the process, an experimental damage modeling software was prepared and used to model two examples of damaged structures from earthquake events. The model instantiation examples illustrate that the proposed as-damaged building data model is capable of expressing not only the final geometry but also the sequence of recording and the presumed failure sequence. During the damage recording process, the status of each identified segment is recorded, as some segments may have broken away and either no longer exist in their original form or they cannot be identified. Although rigorous testing will only be possible once extensions to the IFC schema are formally proposed and adopted through the standard process, no limitations were identified in the tests performed. Tests with full-scale models are ongoing.

The damaged building model instance can be exported in two ways, either as a full record that includes the explicit damage sequence information, or as a partial 'results-only' model 
in which only the final geometry is available. The latter representation can be exported according to the existing IFC4 schema, by filtering segments' status for EXISTING and exporting their geometry as IfcBuildingElement instances with the same shape representation. Other semantic information, including classification, material, reference to spatial structures, etc., can also be exported because it can be traced through the relationship between each as-built element and the root of the damaged segments.

This research was limited to consideration of reinforced concrete structures and to structural elements only. Additional work will also be needed to establish the requirements of first-responders for information other than structural information that could conceivably be incorporated in the as-damaged building model.

Future research will test the data modeling schema's ability to support representation of damaged buildings for two more use cases: laser scanning and photogrammetry of facades post-disaster and reconstruction of the damaged BIM model; compilation of potential asdamaged cases from as-built models using structural collapse simulation for later (postdisaster) selection of a full damaged model case.

\section{Acknowledgment}

This research was funded in part by the Insurance Companies Association of Israel and by the Higher Education Council's scholarship award to the first author. Dr. Ma is supported in part at the Technion by a fellowship from Israel Council for Higher Education. The assistance of undergraduate research assistants Ashrant Aryal and Zhaoxin Fu is greatly appreciated. 


\section{Reference}

[1] Y. Li, Assessment of Damage Risks to Residential Buildings and Cost-Benefit of Mitigation Strategies Considering Hurricane and Earthquake Hazards, Journal of Performance of Constructed Facilities. 26 (2012) 7-16.

[2] G. Guven, E. Ergen, Identification of local information items needed during search and rescue following an earthquake, Disaster Prevention and Management. 20 (2011) $458-472$.

[3] H. Tiedemann, Earthquakes and volcanic eruptions: a handbook on risk assessment, Swiss Re, 1992.

[4] FederalEmergencyManagementAgency, Evaluation of Earthquake Damaged Concrete and Masonry Wall Buildings: Basic Procedures Manual-FEMA 306, 1998.

[5] E. Ergen, S. Sariel-Talay, G. Guven, G. Avdan, Local Information Access for Search and Rescue Using Wireless Data Storage Mediums, Journal of Computing in Civil Engineering. 25 (2011) 263-274.

[6] Z. Aziz, F. Pena-Mora, A. Chen, T. Lantz, Supporting urban-emergency response and recovery using RFID-based building assessment, Disaster Prevention and Management. 18 (2009) 35-48.

[7] R. Zeibak-Shini, R. Sacks, S. Filin, Toward generation of a Building Information Model of a deformed structure using laser scanning technology, in: 14th International Conference on Computing in Civil and Building Engineering (ICCCBE), 2012.

[8] M. Torok, M. Golparvar-Fard, K. Kochersberger, Image-Based Automated 3D Crack Detection for Post-disaster Building Assessment, Journal of Computing in Civil Engineering. 28 (2014) a4014004.

[9] S. German, J. Jeon, Z. Zhu, C. Bearman, I. Brilakis, R. DesRoches, et al., Machine Vision-Enhanced Postearthquake Inspection, Journal of Computing in Civil Engineering. 27 (2013) 622-634.

[10] I. Brilakis, M. Lourakis, R. Sacks, S. Savarese, S. Christodoulou, J. Teizer, et al., Toward automated generation of parametric BIMs based on hybrid video and laser scanning data, Advanced Engineering Informatics. 24 (2010) 456-465.

[11] T. Bloch, Towards Building Information Modeling of Damaged Buildings to Guide Search and Rescue Operations, Technion, 2014.

[12] A.G. Sextos, A.J. Kappos, K.C. Stylianidis, Computer-aided pre- and post-earthquake assessment of buildings involving database compilation, GIS visualization, and mobile data transmission, Computer-Aided Civil and Infrastructure Engineering. 23 (2008) 59-73.

[13] BuildingSmart, Industry Foundation Classes Release 4 (IFC4).

[14] L.G. Dong, J. Shan, A comprehensive review of earthquake-induced building damage detection with remote sensing techniques, Isprs Journal of Photogrammetry and Remote Sensing. 84 (2013) 85-99.

[15] C. Schweier, M. Markus, Classification of collapsed buildings for fast damage and loss assessment, Bulletin of Earthquake Engineering. 4 (2006) 177-192.

[16] W. Liu, P.L. Dong, J.B. Liu, H.D. Guo, Evaluation of Three-Dimensional Shape Signatures for Automated Assessment of Post-Earthquake Building Damage, Earthquake Spectra. 29 (2013) 897-910. 
[17] L. Lu, H. Guo, C. Corbane, Building Damage Assessment with VHR Images and Comparative Analysis for Yushu Earthquake, China, Disaster Advances. 6 (2013) 3744.

[18] S. Okada, N. Takai, Classifications of structural types and damage patterns of buildings for earthquake field investigation, in: Proceedings of the 12th world conference on earthquake engineering (paper 0705), Auckland, 2000.

[19] Z. Zhu, I. Brilakis, Comparison of civil infrastructure optical-based spatial data acquisition techniques, Journal of Computing in Civil Engineering. 23 (2009) 170177.

[20] ISO, ISO 10303-11, Industrial automation systems and integration - Product data representation and exchange — Part 11: description methods: The EXPRESS Language Reference Manual, (2004).

[21] S.H. Lee, B.G. Kim, IFC Extension for Road Structures and Digital Modeling, in: L.H. Fai (Ed.), Proceedings of the Twelfth East Asia-Pacific Conference on Structural Engineering and Construction, Elsevier Science Bv, Amsterdam, 2011: pp. 10371042.

[22] G. Arthaud, E. Lebegue, IFC-Bridge v2 data model: Edition R7, IAI French Chapter Report, February. (2007).

[23] R. Sacks, I. Kaner, C.M. Eastman, Y.S. Jeong, The Rosewood experiment - Building information modeling and interoperability for architectural precast facades, Automation in Construction. 19 (2010) 419-432.

[24] C.M. Eastman, R. Sacks, Y.-S. Jeong, I. Kaner, Building Information Modeling (BIM) for Precast Concrete, National Institute of Building Sciences, Washington DC, USA, 2007.

[25] Z.L. Ma, Z.H. Wei, W. Song, Z. Lou, Application and extension of the IFC standard in construction cost estimating for tendering in China, Automation in Construction. 20 (2011) 196-204.

[26] Z.L. Ma, Z.H. Wei, X.D. Zhang, Semi-automatic and specification-compliant cost estimation for tendering of building projects based on IFC data of design model, Automation in Construction. 30 (2013) 126-135.

[27] Y. Ji, A. Borrmann, J. Beetz, M. Obergriesser, Exchange of Parametric Bridge Models Using a Neutral Data Format, Journal of Computing in Civil Engineering. 27 (2013) 593-606.

[28] Y.H. Lin, Y.S. Liu, G. Gao, X.G. Han, C.Y. Lai, M. Gu, The IFC-based path planning for 3D indoor spaces, Advanced Engineering Informatics. 27 (2013) 189-205.

[29] K.U. Gokce, H.U. Gokce, P. Katranuschkov, IFC-Based Product Catalog Formalization for Software Interoperability in the Construction Management Domain, Journal of Computing in Civil Engineering. 27 (2013) 36-50.

[30] J.P. Zhang, F.Q. Yu, D. Li, Z.Z. Hu, Development and Implementation of an Industry Foundation Classes-Based Graphic Information Model for Virtual Construction, Computer-Aided Civil and Infrastructure Engineering. 29 (2014) 60-74.

[31] G. Lee, Y.H. Park, S. Ham, Extended Process to Product Modeling (xPPM) for integrated and seamless IDM and MVD development, Advanced Engineering Informatics. 27 (2013) 636-651.

[32] NBIMS-US, The National BIM Standard-United States ${ }^{\mathrm{TM}}$ (NBIMS-US $^{\mathrm{TM}}$ ), http://www.nationalbimstandard.org/. 
[33] Earthquake Engineering Research Institute, Earthquake Photo Galleries, https://www.eeri.org/cohost/member-resources/.

[34] Microsoft Visual Studio, http://www.visualstudio.com/.

[35] IfcQuickBrowser, http://www.team-solutions.de.

[36] Eigen, http://eigen.tuxfamily.org/.

[37] VTK, http://www.vtk.org/.

[38] M. Venugopal, C.M. Eastman, R. Sacks, J. Teizer, Semantics of model views for information exchanges using the industry foundation class schema, Advanced Engineering Informatics. 26 (2012) 411-428. 